\title{
La Oficina Internacional del Trabajo en México: la visita de Edward J. Phelan y Stephen Lawford Childs en mayo de 1933
}

\author{
Escritório Internacional do Trabalho no México: a visita de Edward J. Phelan e \\ Stephen Lawford Childs em maio de 1933
}

The International Labor Office in Mexico: the visit of Edward J. Phelan and Stephen Lawford Childs in May 1933

Fabian Herrera Leon*

Universidad Michoacana de San Nicolás de Hidalgo (UMSNH), Morélia, Michoacán, México

\begin{abstract}
RESUMEN: El primer contacto oficial de la Oficina Internacional del Trabajo con México, tras su particular y desgastante proceso de admisión, fue protagonizado por dos de sus funcionarios en mayo de 1933. La estancia breve pero fructífera de Edward J. Phelan y Stephen Lawford Childs, representantes del internacionalismo ginebrino, contribuiría como ningún esfuerzo previo a afianzar y dar cauce a una relación por construir, capaz de ofrecer beneficios a ambas partes con base en un mejor conocimiento mutuo. Este artículo pretende dar cuenta no tanto de los orígenes de la relación como de su verdadero punto de partida y dinamización, poniendo especial atención en las inquietudes de las autoridades mexicanas, sindicales y patronales respecto de su lugar en la organización (tripartismo) y de su exclusividad representativa (rivalidad entre centrales obreras); así como de las necesidades y oportunidades de la Organización Internacional del Trabajo ante este nuevo miembro y actor en sus Conferencias Internacionales del Trabajo. Esta importante misión, como el propio Phelan lo reconocería, se beneficiaría del consejo y acompañamiento otorgado por la diplomacia republicana española en la persona de su embajador en México Julio Álvarez del Vayo.
\end{abstract}

PALABRAS CLAVE: Organización Internacional del Trabajo (OIT). Oficina Internacional del Trabajo (BIT). Edward J. Phelan. Stephen Lawford Childs. Cámara Nacional del Trabajo. Julio Álvarez del Vayo.

RESUMO: O primeiro contato oficial do Escritório Internacional do Trabalho com o México depois do seu particular e cansativo processo de admissão foi protagonizado por dois dos seus funcionários, em maio de

\footnotetext{
* Professor do Departamento de Historia Latinoamericana da Universidad Michoacana de San Nicolás de Hidalgo (UMSNH), Morélia, Michoacán, México. E-mail: fabianhl@hotmail.com. https://orcid.org/0000-0002-9101-0137.
} 
1933. A estadia dos representantes do internacionalismo genebrino, Edward J. Phelan e Stephen Lawford Childs, foi breve, mas frutifera. Ela contribuiria como nenhum esforço prévio a afiançar e dar causa a uma relação em construção, capaz de oferecer beneficios a ambas as partes a partir de um melhor conhecimento mútuo. Este artigo tenta dar conta não tanto das origens do relacionamento como de seu verdadeiro ponto de partida e revitalização, prestando atenção especial às preocupações das autoridades mexicanas, sindicais e patronais em relação ao seu lugar na organização (tripartite) e da sua exclusividade representativa (rivalidade entre centrais de trabalho); assim como das necessidades e oportunidades da OIT ante um novo membro e ator nas suas Conferências Internacionais do Trabalho. Esta importante missão, como Phelan o reconheceria, se beneficiaria do aconselhamento e acompanhamento dado pela diplomacia republicana espanhola na pessoa do seu embaixador no México, Julio Álvarez del Vayo.

PALAVRAS-CHAVE: Organização Internacional do Trabalho (OIT). Escritório Internacional do Trabalho (BIT). Edward J. Phelan. Stephen Lawford Childs. Câmara Nacional do Trabalho. Julio Álvarez del Vayo.

\begin{abstract}
The first official contact of the International Labour Office with Mexico, after its particular and exhausting admission process, was carried out by two of its officials in May 1933. The brief but fruitful stay of Edward J. Phelan and Stephen Lawford Childs, representatives of Geneva internationalism, would contribute like no previous effort to strengthen a relationship to be built, capable of offering benefits to both parties based on better mutual knowledge. This article tries to give an account not so much of the origins of the relationship as of its true starting point and revitalization, paying special attention to the concerns of the Mexican government, union and employer authorities regarding their place in the organization (tripartism) and their representative exclusivity (conflict between workers' centrals), as well as the needs and opportunities of the International Labour Organization before this new member and actor in its International Labour Conferences. This important mission, as Phelan himself would recognize, would benefit from the advice and support given by Spanish republican diplomacy in the person of its ambassador to Mexico, Julio Álvarez del Vayo.
\end{abstract}

KEYWORDS: International Labour Organization (ILO). International Labour Office (BIT). Edward J. Phelan. Stephen Lawford Childs. National Chamber of Labor. Julio Álvarez del Vayo.

Ayudandos con vuestra experiencia, no critiquéis nuestras dificultades. Albert Thomas a los miembros latinoamericanos de la OIT Conferencia del Trabajo, Ginebra, 1932

\title{
Antecedentes de una nueva relación
}

El ingreso de México en la Organización Internacional del Trabajo (OIT) no tuvo lugar sino hasta septiembre de 1931, doce años después de que esta organización centenaria fuera creada en el marco de la Conferencia de Paz de París mediante la inclusión de su Constitución en el Tratado de Versalles (junio de 1919). ${ }^{1}$ Cuatro meses más tarde dio inicio a sus trabajos con la reunión de su primera Conferencia en Washington, en la que tomaron parte las potencias vencedoras en la guerra y las naciones invitadas, bien por su condición de neutrales en la gran guerra o por su reciente creación tras la desintegración de los imperios otomano y austro-húngaro. Con la notable excepción de Estados Unidos, cuya paradójica ausencia es bien conocida, estos serían los miembros integrantes de la constelación de organismos multilaterales que tendrían como eje la Sociedad de Naciones y 
Ginebra como su epicentro. La revolución mexicana terminó siendo ajena a todo esto de acuerdo con una lógica complicada de definición interior, pretendida por sus diversas facciones, y de autoconservación frente al exterior, percibido como refractario y amenazante para la consolidación del régimen que iba tomando forma. La conveniente exclusión mexicana del sistema de Versalles sería determinada por una indiscreta germanofilia durante la guerra y una creciente dimensión de afectaciones a bienes e inversiones extranjeros, en especial, los relacionados con la explotación del subsuelo por metales o petróleo (HERRERA LEÓN, 2020, p. 1647-1680). Su omisión en la lista de potencias neutrales invitadas a adherir al Tratado de Versalles y a su revolucionario sistema de organizaciones multilaterales estaría, pues, en armonía con su propia antipatía y desconfianza hacía artífices; un hecho que configuraría una situación excepcional nada fácil de superar y que supondría iniciativas complicadas y efímeras de aproximación, especialmente, entre México y la Oficina Internacional del Trabajo (BIT), ${ }^{2}$ el organismo directivo permanente de la organización laboral internacional. Aquí, en este mutuo descubrimiento y búsqueda de colaboración formal al margen de una membresía societaria cabal y a la postre imposible, están los orígenes de la relación cuya dinamización posterior será objeto de atención en este artículo y que nos remite igualmente a una condición historiográfica sobre la que cabría detenerse un poco también.

Esta es una condición de descuido académico incomprensible ante prácticamente toda la dimensión histórica de la relación entre México y la OIT, tanto de las primeras décadas de trato oficioso y formal, como del pasado reciente; de modo tal que la comprensión y análisis de la relación sigue sujeta a las necesidades de una interpretación técnica inmediata sin suficiente perspectiva histórica. Se ha escrito, pues, mínima y ocasionalmente sobre cien años de trato con la organización y la compleja cuestión del trabajo y sus condiciones en el mundo, obviando el desempeño de una variedad de gobiernos, políticas, tipos de representación tripartita (gobierno, obreros y patrones), retroalimentación y medios de entendimiento oficial y oficioso (correspondiente). ${ }^{3}$ No obstante, esta problemática histórica podría considerarse indirectamente beneficiada por los aportes historiográficos para el ámbito latinoamericano en las últimas décadas, cuyo propósito ha sido tanto la generación de conocimiento nuevo como la revisión de interpretaciones histórico-políticas previas, así como la definición de un paradigma que permita la comprensión del fenómeno transnacional protagonizado por los organismos, redes y actores internacionales del periodo de entreguerras en tanto que concertantes de acuerdos comunes y difusores de modelos y normativas con un potencial de adaptación global. ${ }^{4}$ Aunque sin una metodología y conceptos propios y exclusivos para su análisis, América Latina ha ganado un especial atractivo, equiparable a un boom problemático (FRENCH, 2000, p. 286-287, p. 298-299), como resultado de este replanteamiento al tratarse de una región que ejemplifica muy bien la posibilidad de retroalimentación al hacer, por una parte, valiosas contribuciones a la cuestión del trabajo en el mundo, tales como el artículo 123 sobre el mismo y la previsión social en la Constitución mexicana de $1917^{5}$ y los códigos laborales mexicano y chileno de 1931; y al protagonizar, por otra parte, un proceso de codificación y legislación de mediana duración (hasta la década de 1960) que observa una pertinente influencia modeladora de parte de la Oficina Internacional del Trabajo y el cuerpo de Convenciones de la organización, así como la atención en persona y en el lugar de sus especialistas (JENSEN, 2011). Esto fue posible gracias a la reorientación de la misma organización como consecuencia del desarrollo de la crisis económica (1929), así como de una especialización técnica de su funcionariado para atender las necesidades americanas de leyes e instituciones de seguridad social. 
La pratique de l'assistance technique - precisa Véronique Plata-Stenger —, fondée sur la difusión de savoirs experts, reflète également une évolution dans la perception du mandat social de l'OIT. Cette évolution s'opère dans le sillage de la crise de 1929 et témoigne d'une prise de conscience de la nécessité de ne plus se borner à fixer des normes, mais de concentrer ses efforts sur l'aménagement et la coordination des politiques sociales (PLATA-STENGER, 2017, p. 61).

América Latina fue la subregión que mejor respondió a este tipo de política y desempeño institucionales, y este es precisamente el contexto de apertura de la misión de especialistas de la OIT en México que interesa a este artículo, mucho más por el despliegue inicial y coordinado en favor de tal legislación y modelación instituciones sociales, un propósito de particular interés que, como es sabido, sería emprendido en 1934, inmediatamente después de la visita de Phelan y Childs y de la designación de un correspondiente relacionado con el proyecto (Federico Bach) pero que no sería retomado sino hasta 1941 y alcanzado dos años después (PLATA-STENGER, 2017, p. 43-48, p. 58). ${ }^{6}$

La modelación continental de la seguridad social se vio igualmente beneficiada por la aclaración amistosa de las relaciones de los países latinoamericanos con Estados Unidos mediante la política del buen vecino (diciembre de 1933) del gobierno de Franklin D. Roosevelt, favorable a una dinamización armoniosa y libre de una política interamericana con un perfil social (reformismo y Estado de bienestar), lo cual lograría mayor congruencia en 1934 con el ingreso de Estados Unidos en la OIT (JENSEN, 2011, p. 223). Contamos, pues, con estas importantes señas y calibraciones válidas para comprender el desempeño de la región en un plano de análisis transnacional y hasta global (VAN DER LINDEN, 2002; BOHÓRQUEZ-MONTOYA, 2009, p. 273-301; CROUCHER; MCILROY, 2013, p. 485-490), enfoques novedosos que como otros antes la incluyen sin conocerla bien, ${ }^{7}$ pero hemos prescindido de todo lo que ha permitido a los especialistas europeos y estadounidenses llegar hasta aquí; así es que nuestra historiografía es fragmentaria y ha estado sujeta a ires y venires - cada vez en menor número - de los estudiosos del trabajo y las cuestiones sociales a ese pasado impreciso; ${ }^{8}$ y el que involucra a la OIT y Ginebra ${ }^{9}$ suele ser uno de estos problemas por definir en lo general en lo que a América Latina respecta. El presente artículo pretende, pues, apreciar el origen de esta sutil e hipotética presencia representativa a través de sus especialistas y esclarecer un vínculo significativo en este dilatado proceso de asentamiento y remodelación de la seguridad social mexicana, referida básicamente a su sistema de pensiones y asistencia médica regular y accidental mediante el Instituto Mexicano del Seguro Social (IMSS, 1943). ${ }^{10}$ Así es que empezaremos por apreciar los antecedentes de la relación y su indiferente puesta en marcha como antesala a la visita de funcionarios internacionales en el contexto de la regionalización activa del BIT y su amplia campaña en favor de la seguridad social. Se hará enseguida una reconstrucción de la misión, destacando la atención en el lugar a los principales problemas y desventajas de la relación y las medidas de atención inmediata a corto plazo. Lograremos entrever así la capacidad de influencia y colaboración técnica del BIT en el proyecto de seguridad social mencionado y más importante para el México posrevolucionario.

Años atrás, por lo que hace a los antecedentes históricos de la relación entre México y la OIT, su primer director, Albert Thomas, había conseguido atraer la atención de los mexicanos y animado el envío de un observador permanente para estudiar los términos de una colaboración formal, en principio posible, pero al final inviable, lejos de la Sociedad de Naciones, como en un primer momento 
pretendió hacerlo la diplomacia mexicana. ${ }^{11}$ Esta sería la principal causa de molestia y enfriamiento del intercambio amistoso entre el BIT y las autoridades mexicanas justo cuando emprendieron una relación formal tras el ingreso de México en la Sociedad de Naciones en septiembre de 1931 vía una negociación directa con el secretario general de esta organización central y no de la búsqueda de resquicios y ambigüedades legales (HERRERA LEÓN, 2011, p. 336-355; HERRERA LEÓN, 2020 , p. 1647-1680). La suspicacia para con la organización laboral, en gran medida alimentada por Salvador Martínez Alba a través de sus cada vez más frustrantes e imbricados informes como observador permanente de México en Ginebra, ${ }^{12}$ muy probablemente terminó por despejarse con el nombramiento de un nuevo director general tras la inesperada muerte de Albert Thomas en mayo de 1932. Este fue el inglés Harold Butler, oportuno aliado político de México en los desproporcionados y sospechosistas informes realizados meses antes por Martínez de Alba. ${ }^{13}$ Y me parece pertinente la referencia puesto que nunca me he encontrado con documentación que acredite diferencias de trato con México de parte de estos primeros directores generales, mucho menos de Edward J. Phelan, quien años después asumiría esta responsabilidad. Por el contrario, Thomas mantuvo su amabilidad característica, siguió promoviendo la organización y sus convenciones, y, en palabras del expresidente Emilio Portes Gil, desde la embajada en París, no dejó de celebrar la ocasión del ingreso en la OIT y siguió revelando "un sincero interés por la opinión de México en cuestiones sociales”. ${ }^{14} \mathrm{El}$ tema entonces - y aún después de la muerte de Thomas - sería el de la adhesión de México a cerca de una veintena de convenciones de la organización concebidas a partir de su primera Conferencia (1919), su firma y ratificación, a sabiendas, precisamente, de su consonancia con la legislación social mexicana, así como de la posibilidad de adherir a la mitad de ellas sin la necesidad de realizar ningún cambio en la legislación laboral mexicana; ${ }^{15}$ cuestión que el propio Thomas planteó a Portes Gil poco después del ingreso de México en la Sociedad de Naciones, epistolar y personalmente en un banquete ofrecido al embajador mexicano en el célebre Hotel Crillon. ${ }^{16}$ Harold Butler, como nuevo director de la OIT, continuaría esta labor de adaptación, eventualmente complicada por los tiempos y formas de la burocracia mexicana, más que otra cosa. Y es difícil interpretarlo de un modo distinto ante la abrumadora regla de notificaciones y consultas excesivas y repetitivas que suelen reflejar los archivos ministeriales de la época y las omisiones de continuidad que merecieron ciertas solicitudes importantes de atención relacionadas con la consideración y aprobación de tales convenciones y recomendaciones planteadas a la Secretaría de Industria, Comercio y Trabajo por parte de la cancillería desde noviembre de $1931 .{ }^{17}$ Esta misma Secretaría, a través de su Oficina de Asuntos Internacionales del Trabajo, concedía ante esta interpretación en su respuesta al informe de la cancillería sobre las estimaciones que el propio Thomas había hecho respecto de la ratificación de ocho Convenciones existentes por parte de México sin necesidad de modificaciones en la legislación laboral vigente; pero tampoco ocultaba cierta antipatía ante la solicitud general de ratificaciones:

Aceptamos en cuanto valen las opiniones del señor A. Thomas, sobre la materia, y aún creemos que son en número superior a ocho los Convenios que pueden ser ratificados, de primera intención, por nuestro gobierno; pero creemos asimismo que no hay razón alguna que pueda justificar un apresuramiento irreflexivo, que acaso pudiera calificarse en Ginebra de ligereza. [...] Si la opinión de los mismos funcionarios de la Oficina Internacional del Trabajo es exacta, como nosotros lo creemos, y la "justicia social — que persigue la Organización — se concibe como una tendencia y no como un estado", es indudable que nuestra legislación obrera responde 
con creces a los fines propuestos; y así lo estiman aquellos funcionarios, a juzgar por las notas de ellos que ha tenido usted la bondad de ordenar se nos transcriban. Próximamente tendré el honor de enviar a usted una relación de los textos de Convenios y Recomendaciones que a juicio de esta Secretaría pueden ser ratificados por nuestro gobierno. ${ }^{18}$

En cuanto a la Conferencia Internacional del Trabajo, México tuvo su primera participación como miembro de pleno derecho en abril de 1932, la última bajo la presidencia de Albert Thomas, pues moriría una semana después de su conclusión. Su representación a esta XVI Conferencia se integró con cierta urgencia un mes antes y prescindió del delegado obrero y patronal, respectivamente, no obstante la petición particular de Thomas a este respecto; ${ }^{19}$ únicamente se contó con la presencia de los dos delegados del gobierno que era posible inscribir. ${ }^{20}$ Muy probablemente esto fuera insuficiente para desplazar la desorientación de la Sociedad de Naciones respecto de México y la contrariedad que Thomas veía en una colaboración renuente pese a la ocasión de una incorporación tan reciente a la Ginebra internacional. Esto lo expresaba con moderación Martínez de Alva a la cancillería desde Ginebra a principios de febrero de 1932, solicitando igualmente la designación de una delegación completa a la Conferencia Internacional del Trabajo. ${ }^{21}$ También Thomas se dirigiría con este propósito al expresidente Plutarco E. Calles, jefe máximo de la revolución y por entonces secretario de Guerra y Marina. ${ }^{22}$ Pese a estas formas de indecisión, la prensa oficialista propiciaba un ambiente claro con motivo de la participación de México en la Conferencia bajo titulares como este: "Nuestro país en la Conferencia Internacional del Trabajo. Importantes temas van a ser debatidos en la importante reunión de Ginebra” (El Nacional, México, D. F., 3 de marzo de 1932). Y la participación mexicana puede considerarse positiva en esta primera Conferencia aunque un tanto arriesgada en razón de la molestia de los representantes obreros ante el envío de una delegación mexicana incompleta, cuestión que el propio Thomas debió atender personalmente y pedir a la Oficina de México en Ginebra, a cargo de Salvador Martínez de Alva, argumentara problemas de presupuesto ante la Comisión de Credenciales. ${ }^{23}$ La cuestión de fondo no era otra sino el que no se hubiera invitado a la Confederación Regional Obrera Mexicana (CROM) - todavía con un buen espectro internacional de relaciones en el medio sindicalista - a asumir esta representación de los trabajadores mexicanos pese a su persistente debilitamiento y abandono invariable de grandes contingentes obreros.

Para terminar - informaba Castillo Nájera - con lo que a estos incidentes se relaciona, me parece oportuno informar que, habiendo recibido el periódico El Universal, de la ciudad de México, correspondiente al 8 de abril, le mostré al delegado Arévalo [el delegado obrero cubano] la noticia referente a que sesenta sindicatos se habían separado de la CROM, con lo que le hice ver la prudencia justificada del gobierno mexicano al no haberse decidido a delegar, en un miembro de aquella, la representación de los obreros de nuestra patria, pues, por más que Arévalo sostiene que es la CROM la genuina representante del laboralismo mexicano, esa creencia le dije, es el resultado de sus personales simpatías, pero, tal vez, no corresponde a la verdad. El gobierno no puede, por lo tanto, sin exponerse a que se le acuse de ligereza, descartar otras organizaciones cuya importancia puede igualar, cuando menos, a la de la CROM. ${ }^{24}$

México no dejó de brindarse un autorreconocimiento en la primera exposición pública en esta organización por parte de Castillo Nájera, también representante de México en la Conferencia del Desarme que corría en paralelo. El extracto de su discurso a continuación es extenso, pero cabe rescatar esta autorreferencia preparada para uno de los escaparates internacionales más visibles en el periodo de entreguerras: 
Hace veintidós años México fue sacudido por una conmoción social; las condiciones políticas y la situación miserable de la población rural y de la clase obrera habían alcanzado un grado intolerable. El edificio de un progreso aparente y de una ficticia prosperidad se derrumbó con una facilidad imprevista. Los acontecimientos mal interpretados o deformados, a los que se mezclaban las calumnias, nos hicieron aparecer como un pueblo anárquico y desordenado. Los autores de la reforma social prosiguieron su tarea llenos de valor y de fe, y el tiempo se ha encargado de hacerles justicia.

La Constitución Federal del 5 de febrero de 1917, en sus artículos 27 y 123, cristalizó las reivindicaciones sociales, fundando una nueva legislación, de acuerdo con los sentimientos y necesidades de la mayoría de la nación.

El artículo 123 engloba la mayor parte de los principios adoptados en las Convenciones y en las Recomendaciones de las Conferencias Internacionales del Trabajo. Los distintos estados que forman la Federación mexicana se apresuraron para reglamentar el artículo de la Constitución, pero precisaba una ley nacional capaz de unir y de hacer uniformes las disposiciones dictadas por los Estados; a esta obra de coordinación y de unidad, el Ejecutivo de la Federación consagró dilatados estudios, logrando formular un código de aplicación general, que corresponde a las realidades prácticas, y conforme con las necesidades del país.

El 27 de agosto del año último, la Ley Federal del Trabajo fue votada por el Congreso e inmediatamente promulgada. La mayoría de las disposiciones se aplicó desde la publicación de la ley, pero fue necesario conceder cortos plazos para la vigencia de algunos artículos, de manera que la ley, en conjunto, no entró en vigor sino el mes de febrero de 1932.

Se cree firmemente que llenará su objeto, realizando, así, las esperanzas de quienes la concibieron. Ya hemos dicho lo mucho que lamentamos el que nos haya sido imposible presentarnos con una delegación completa; el gobierno espera que en lo porvenir logrará sobreponerse a las dificultades de orden material que le impidieron, en esta vez, llenar la obligación de que se trata.

Nuestro ingreso a la Sociedad de las Naciones coincidió con un periodo parlamentario que tocaba a su fin; por esta causa el Congreso no conoció las Convenciones y Recomendaciones que esperan ratificación. Sin embargo, podemos asegurar que el Ministerio de Industria, Comercio y Trabajo se ocupa activamente en preparar los documentos que serán sometidos a la consideración del Congreso en el curso de su reunión siguiente. El Ministerio cuenta con que un número apreciable de ratificaciones será comunicado a la Conferencia próxima. ${ }^{25}$

La Conferencia concluyó con dos recomendaciones importantes para México de acuerdo con el informe de Blasquez, el otro representante mexicano, el cual extractaría la cancillería para conocimiento de la Secretaría de Industria, Comercio y Trabajo: el envío de una delegación completa, sin olvidarse de los delegados obrero y patronal; ${ }^{26}$ y no solo la ratificación de las Convenciones y Recomendaciones como también su ejecución y observación, respectivamente. ${ }^{27}$ La disposición de la Oficina de Asuntos Internacionales del Trabajo dejaría, sin embargo, un tanto qué desear y advertiría sobre la necesidad aún pendiente de convencimiento en algunas sectores clave, como este, dentro del gobierno mexicano:

Es verdad que en esta última Conferencia, el Presidente de la Asamblea afirmó que los Estados miembros tienen obligación de enviar completas sus delegaciones a estas reuniones generales; pero tal obligación moral no lleva aparejada siempre la posibilidad económica, y la realidad se empeña a veces en contrariarla. No constituye, desde luego, una excepción insólita la presencia de la delegación mexicana incompleta, puesto que, como lo hice notar en otra ocasión, a la Conferencia general reunida en 1931 se presentaron 16 delegaciones incompletas, y en la 
última volvieron a presentarse otras 16 incompletas, con la agravante de la ausencia total de unos 8 Estados miembros.

Por lo que se refiere a la obligación moral para cada Estado, de proponer al término de un año, que sean ratificados los proyectos de Convenios que aprueba la organización, es pertinente hacer la recordación que sigue: varios países, como la Argentina, Perú, Guatemala y El Salvador, no ha registrado ninguna ratificación de Convenios, a pesar de que pertenecen a dicha organización desde la fecha en que esta fue creada, y su actitud no provoca dificultades, ni ha suscitado censuras; en cambio, la actitud que adoptó el último de esos países, cuando, siendo miembro de la Sociedad de Naciones quiso no participar en la Organización del Trabajo, en 1920, sí provocó discusiones muy insistentes. ${ }^{28}$

Aunque preciso y meticuloso en su crítica, Villa Michel construía básicamente un argumento refractario que no correspondía con la realidad de un país que incursionaba decididamente en el ámbito de la política internacional. La propia oficina a su cargo dentro de la Secretaría de Industria, Comercio y Trabajo lo contrariaba. Precisamente, un antecedente más a tener en cuenta era este. México había dado lugar a un par de formalidades administrativas muy sugerentes de la importancia que en principio daba a su internacionalización, en gran medida a través de los organismos ginebrinos con la creación de dos oficinas de atención dentro de las secretarías de Relaciones Exteriores y de la de Comercio, Industria y Trabajo; respectivamente, la referida Oficina Mexicana en la Sociedad de Naciones y la Sección Sociedad de Naciones dentro del Departamento Diplomático de la cancillería, así como la Oficina de Asuntos Internacionales del Trabajo en la otra Secretaría.

Entre el 8 y 30 de junio de 1933, un mes después de la visita de Phelan y Childs, tendría lugar la XVII Conferencia Internacional del Trabajo en Ginebra y a la que México envío una delegación pequeña pero completa, integrada por las tres representaciones requeridas por la misma: Manuel Martínez Báez, como delegado gubernamental; Elías F. Hurtado en representación de los trabajadores y Ulises Irigoyen como delegado patronal, con la asistencia de Carlos Prieto. Francisco Castillo Nájera se desempeñaría por segunda ocasión como jefe de la delegación. ${ }^{29}$ El problema en ello, aunque se trata de una cuestión que escapa a este estudio, es que el acuerdo para el nombramiento de esta delegación, con excepción de Castillo y Prieto, fuera emitido desde Palacio Nacional por el propio presidente de México. ${ }^{30}$

\section{El anuncio de la visita y los personajes}

Harold Butler tomaría las riendas de la organización laboral que había ayudado a fundar en una de las etapas más complicadas de su historia. Su dirección comprendió la extensión de la crisis económica internacional y sus consecuencias en el mundo laboral, así como el periodo de creciente debilitamiento de su soporte institucional, la Sociedad de Naciones, equivalente a la derrota práctica del multilateralismo entre la Conferencia del Desarme y la crisis de los Sudetes. Pero esta puede considerarse igualmente una década de fortalecimiento para la OIT en la medida en que Butler dirigió sus esfuerzos a internacionalizarla desde dentro, con un funcionariado y colaboradores leales e imbuidos de esta lógica y misión supranacional, y desde fuera, con incorporaciones de gran importancia como la de Estados Unidos en 1934, de un mayor número de naciones ultraeuropeas en su Consejo de Administración y de una colaboración mayor y en el lugar con países y regiones fuera de Europa, América Latina entre ellas, sede en 1936 de una Conferencia Regional 
en Santiago de Chile. Sin duda toda esta obra confirmatoria de la misión independiente de la OIT en el mundo contribuyó a su supervivencia sin sufrir modificaciones que la presentaran como un organismo distinto en la posguerra.

Esta dinámica de internacionalización a la que nos hemos referido explicaría no solo la notable visita de importantes directores de área de la organización como Phelan y Childs, sino también la inmediata contratación de un correspondiente permanente en México. Como único antecedente mencionable está la visita a mediados de 1925 de Paul Devinat, enviado meteóricamente por Thomas para tratar, como tema principal con el presidente Calles, el envío de refugiados rusos. ${ }^{31}$

La visita a México del director de la División Diplomática de la Oficina Internacional del Trabajo, Edward J. Phelan, fue anunciada casi con dos meses de antelación, a principios de abril de 1933. El anuncio fue hecho en persona al ministro Castillo Nájera por el director de la OIT y el propio Phelan. Se habló entonces de una visita de cortesía en el marco de una gira del funcionario por Norteamérica y en razón de la incorporación reciente de México en la organización. Esta misión tendría que anteceder a la de una Comisión Oficial prevista un año después, a fin de realizar "importantes e inéditos estudios sobre las condiciones sociales de los trabajares en México". ${ }^{32}$ Butler se dirigió al secretario de Relaciones Exteriores de México veinte días después para hacer el anuncio formal de la estancia breve del jefe de la División Diplomática de la Oficina y de su subjefe de Gabinete, Stephen Lawford Childs, quienes llegarían al país - cruzando por Laredo - el día 22 de mayo para el desenlace de la gira norteamericana emprendida en Canadá. ${ }^{33}$

Edward J. Phelan, un artífice más de la organización laboral en la Conferencia de París, asumió desde la dirección de Thomas el puesto de primer funcionario de la OIT como jefe de la División Diplomática. Este internacionalista irlandés formado en Liverpool continuaría una trayectoria sostenida en puestos directivos a partir precisamente de 1933 hasta ser nombrado en 1946 director general de la organización con efecto retroactivo hasta 1941, año de la dimisión del estadounidense progresista John Winant, quien trasladaría la Oficina Internacional del Trabajo a Montreal para evitar su completo aislamiento. Como director de la OIT, Phelan consiguió con limitados recursos y personal convocar a dos reuniones importantes en Nueva York (1941) y Filadelfia (1944) y mantener su trabajo de consulta y publicaciones, especialmente de la añeja Revista Internacional del Trabajo, antes de hacer frente al difícil proceso de negociación en la posguerra que permitiría su continuidad histórica como organismo especializado de las Naciones Unidas.

Aunque escasa, la información acerca del escritor y diplomático inglés Stephen L. Childs es muy sugerente antes y después de su viaje a México en compañía de Phelan. Adscrito a Rusia como agregado comercial - y espía - durante la revolución, había trabajado en el sur de Rusia en la reconstrucción económica de las áreas antibolcheviques (1918-1920), para después ocuparse de la cuestión de los refugiados rusos desde la Sociedad de Naciones y de la vinculación de la OIT con Sudamérica hasta el estallido de la guerra y su muerte en un traslado aéreo entre Bagdad y Teherán (EDMOND, 2017, p. 114; HARDY, 2004, p. 329). Childs llevó a cabo el mayor número de visitas oficiales al continente americano en representación de la Oficina Internacional del Trabajo y en calidad de jefe de Gabinete del director general. Entre 1933 y 1937, sus visitas y estancias breves comprendieron Canadá, Estados Unidos, México, Brasil, Argentina, Uruguay, Perú y Chile, así como los trabajos relacionados con la Conferencia de Santiago en enero de 1936.

Phelan y Childs no serían los únicos agentes del internacionalismo ginebrino en actividad durante estos años. En representación de la misma OIT tendrían una presencia importante su propio director general, Harold Butler (1935-1936), así como el jefe de la Sección de Seguridad 
Social, Adrien Tixier (1934), y de Fernand Maurette (1936), director asistente. Además de cultivar mejores relaciones y lealtad entre sus miembros latinoamericanos, con extensión a una segunda Conferencia en La Habana (diciembre de 1939), la OIT presenciaría así el proceso regional de industrialización, así como de desajuste en los intercambios internacionales como consecuencia de la crisis económica y del avance de nuevos proveedores, cuyos usos de la fuerza de trabajo rivalizarían con los de Europa Occidental: URSS, Japón y Alemania. Así es que en el fondo se trataba de terminar de moldear y definir con claridad los rasgos comunes de la cuestión social en ese extremo occidental americano; estos fueron los niveles posibles de seguridad social gracias a la asistencia técnica de la OIT, aprovechando la capacidad de convocatoria estadounidense en favor del interamericanismo (FERRERAS, 2019, p. 41-45; PLATA-STENGER, 2017, p. 47-49). "La nouvelle politique regionale de l'OIT - escribe Plata-Stenger - lui permet de dresser son drapeau sur tout le continente latino-américain. Les conférences regionales de l'entre-deux-guerres sont complétées par la mise en place des mécanismes de la cooperation technique dans le domaine des assurances sociales" (PLATA-STENGER, 2017, p. 51). Este tipo de cooperación técnica bien podría tener por antesala tal paso de funcionarios ginebrinos y propiciar una colaboración con la OIT en la elaboración de leyes del trabajo y sistemas de seguridad social.

\section{Desarrollo de la misión}

Edward J. Phelan y Stephen L. Childs llegaron a la ciudad de México el 22 de mayo de 1933 por la mañana y fueron recibidos en la estación de tren por personal del Departamento del Trabajo, pero no por su titular, Juan de Dios Bojórquez, quien atendía personalmente otros asuntos fuera de la ciudad. Phelan lamentaría esta situación al inicio de la visita, pues aunque fueron asistidos por funcionarios del Departamento del Trabajo para conocer su organización y administración de la legislación laboral en el país, no tenían la autoridad "[...] para discutir los aspectos políticos de las relaciones entre México y la Oficina Internacional del Trabajo". ${ }^{44}$ Al final de su estancia conseguirían verlo, una vez Bojórquez regresó en avión a la ciudad para unirse a una de las últimas actividades organizadas con motivo de la visita de los funcionarios ginebrinos, quienes dedicarían estos primeros días al reconocimiento del Departamento del Trabajo y de la cuestión laboral en el país, advirtiendo que "Los funcionarios están al tanto de nuestras publicaciones y tienen un buen conocimiento de nuestra Organización. Sin embargo, no están muy bien enterados de nuestras Convenciones ni de las posibilidades de sus ratificaciones".35

La visita se desarrollaría en un momento especial de la política mexicana determinado por las precandidaturas presidenciales afines al Partido Nacional Revolucionario, principalmente las de Lázaro Cárdenas y la de Manuel Pérez Treviño, dirigente del partido llamado a ser hegemónico y favorito de la organización obrera creada para contrarrestar y eventualmente sustituir a la CROM: la Cámara Nacional del Trabajo (LÓPEZ VILLAFAÑE, 2005, p. 121). Su secretario general, Alfredo Pérez Medina, antiguo líder cromista, fue presentado en el mismo Departamento del Trabajo a Phelan y Childs, quienes realizaron una visita especial a los talleres de impresión nacional que estaban igualmente bajo su dirección. El problema en relación con estas centrales obreras pasaba por la representación de los trabajadores en la Conferencia Internacional del Trabajo, y sobre el tema pudo hablarse con el secretario de Relaciones Exteriores Manuel Puig Casauranc. Aunque la CROM venía perdiendo sindicatos y miembros adherentes en beneficio de la nueva 
central que contaba con el favor del gobierno, esta, como lo reconocía el canciller, aún no parecía ser tan numerosa como para ser considerada representativa de los trabajadores mexicanos, aunque quedó muy en claro que sería cuestión de tiempo que esto fuera así y que una futura delegación mexicana ante la Conferencia incluyera siempre a uno de sus agremiados. Las opiniones sobre la Cámara fueron en lo general bastante positivas en el informe de Phelan al director de la OIT:

La Cámara publica un numeroso y bien editado periódico llamado Unificación, en el que estuve muy interesado al encontrar una voluminosa y precisa información de la Conferencia preparatoria de las cuarenta horas. No hay ninguna duda de que la Cámara está bien organizada e inteligentemente dirigida. ${ }^{36}$

Respecto de la CROM, cuya visita fue hasta cierto punto procurada por el propio Phelan tras un encuentro breve con el presidente Abelardo L. Rodríguez, las impresiones fueron menos cálidas. No solo estuvieron presentes su secretario general, Eucario León López, sino Luis N. Morones y sus más importantes funcionarios y líderes sindicales. La ocasión fue limitadamente aprovechada por los cromistas para desacreditar las demás centrales obreras, argumentar conspiraciones en su contra y lanzar acusaciones infundadas en contra de Elías F. Hurtado, quien representaría a los obreros en la XVII Conferencia Internacional del Trabajo de junio de $1933 .{ }^{37}$ Phelan y Childs entrarían en contacto con algunas otras organizaciones obreras y patronales con manifestaciones más amistosas, inclusive populistas. ${ }^{38}$

Con el canciller Puig Casauranc se trataría igualmente el tema de la ratificación de convenciones y recomendaciones internacionales:

El Sr. Childs - informaría Phelan — hizo numerosas visitas al secretario de Relaciones Exteriores y fue exitoso en conseguir entrar en contacto personal con los funcionarios directamente involucrados con las formalizaciones requeridas para las ratificaciones. Fue, creo, enteramente debido a estos esfuerzos que todo el procedimiento fue acelerado y que la temprana ratificación de ocho convenciones además de la del artículo 393 fue posible. ${ }^{39}$

Fritz Sulzbacher, suizo alemán conocido en México como Federico Bach, con una aventurada trayectoria en el país y por entonces subdirector general de estadística, fue presentado igualmente con los funcionarios ginebrinos como colaborador recurrente del Departamento del Trabajo, especializado en cuestiones de legislación social (HERRERA LEÓN, 2013, p. 99-124; HERRERA LEÓN, 2017, p. 239-267). Phelan vio en él un candidato idóneo para ser contratado como correspondiente permanente de la OIT en México, aprovechando su ubicación estratégica entre la información estadística y su cercana relación con el Departamento del Trabajo:

Me dio la impresión de ser bastante inteligente y de tener un conocimiento más allá de sus temas de legislación, estadística y seguridad social, sino también de la ley laboral mexicana y de su administración. Si tuviéramos que considerar el nombramiento de un correspondiente en México, no dudaría en recomendarlo como la persona más indicada. ${ }^{40}$

La visita internacional cerró con una reunión convocada con este propósito por el representante en México de la afín segunda república española, el embajador Julio Álvarez del Vayo. ${ }^{41}$ En la reunión estuvo presente Bojórquez, además de Puig Casauranc, el ex presidente Portes Gil, quien fue 
además el primer representante de México ante la Asamblea de la Sociedad de Naciones (septiembre de 1931), y los principales funcionarios del Departamento del Trabajo y de la Secretaría de Relaciones Exteriores. La ocasión con Bojórquez, especialmente, fue bien aprovechada para anticipar los ataques de la CROM en la Conferencia Internacional del Trabajo que se celebraría el mes siguiente, en lo que respecta particularmente a la representación obrera que pretendían reivindicar. ${ }^{42}$

Phelan haría el siguiente balance de la misión:

Pienso que podríamos decir que la misión a México fue extremadamente útil. La misión indudablemente se llevó a cabo con dificultades que deben explicarse por el hecho de que representó el primer contacto entre la Oficina y las autoridades mexicanas. No había, pues, una base sobre la cual estimar la importancia de la misión y, aunque estaban bien informados en lo general respecto de la estructura de la Organización Internacional del Trabajo, no tenían ningún conocimiento de los métodos para una colaboración activa con ella. Los primeros contactos que ahora se han hecho darán indudablemente futuras relaciones que sean más sencillas. Además, largamente debido a las intervenciones del Sr. Childs con los funcionarios de la cancillería, una primera tanda de ratificaciones puede verse como cierta [...] La cuestión de las credenciales de los trabajadores mexicanos no parece presentar ningún problema para la Conferencia [...] Las bases para una cercana colaboración han sido echadas y será posible construir sobre ellas en el futuro [...] En el caso de la misión a México, el consejo y la asistencia del embajador español, Vayo, fue de enorme ayuda. ${ }^{43}$

\section{La definición de un cauce, a modo de conclusión}

En 1934, el Departamento del Trabajo integró una comisión encargada de preparar un proyecto legislativo sobre seguridad social, la cual perfiló como obligatoria - y no optativa como en el resto de América Latina con excepción de Chile - y en sentido amplio respecto de los accidentes de trabajo, las enfermedades, la maternidad, el retiro y el desempleo. Tal propuesta, como lo aprecia Véronique Plata-Stenger, debería mucho a Federico Bach, correspondiente de la OIT en México en contacto regular con Butler, y miembro de esta comisión especial. ${ }^{44}$ Como es sabido, esta ley de seguridad social habría de ser pospuesta estratégicamente por el gobierno de Lázaro Cárdenas a fin de no lidiar al mismo tiempo con una cuestión que podría complicarse tanto como la petrolera, ${ }^{45}$ y sin que ello supusiera una mengua en el respaldo que el sindicalismo mexicano ofrecía a este régimen movilizador de masas (ZAPATA, 2010, p. 66-67). En 1941, la OIT enviaría a México personal experto para definir el soporte financiero de un proyecto de seguridad social finalmente retomado y adoptado dos años más tarde con el nombre de Instituto Mexicano del Seguro Social (PLATA-STENGER, 2017, p. 48).

Por lo que hace a la ratificación de convenciones y acuerdos internacionales diversos, a principios de diciembre de 1932, Manuel C. Téllez, en su calidad de secretario de Relaciones Exteriores, envió al Senado una serie importante de estos, adoptados en el marco de distintas Conferencias del Trabajo posteriores a $1925 .{ }^{46}$ Veinte días más tarde fueron ratificados e inclusive se habló de su formalización definitiva en el marco de la misión de Phelan y Childs, pero esto no ocurrió sino hasta marzo de 1934 mediante su refrendo por la Presidencia de la república y la cancillería y su inscripción ante la Secretaría General de la Sociedad de Naciones a principios de mayo del mismo año. $^{47}$ 
El factor dinamizador de la relación entre México y la Organización Internacional del Trabajo, que será un hecho tras la visita de Phelan y Childs, tendrá que ver precisamente con el establecimiento de vínculos personales y profesionales con un beneficio mutuo a mediano plazo. Desde finales de 1934 y en un lugar muy especial se ubicará dentro de esta red de relaciones dinamizadas el correspondiente de la OIT en México, figura clave en la interiorización de modelos y conceptos de confección ginebrina, además de un estratégico agente informativo tanto en un plano técnico y estadístico como en otro social y político. La OIT, por su parte, vería afianzarse entre sus miembros a uno de los principales referentes contemporáneos de revolución, coartífice del constitucionalismo social del siglo XX y actor destacado en su ámbito regional latinoamericano y en la escena ginebrina de entreguerras.

Han pasado cien años desde el momento del impulso más importante que históricamente se haya dado a la interacción humana en un plano supranacional de orden político, económico y social. Algunas de sus implicaciones podrían no sernos del todo ajenas ni desconocidas, pero en todo caso hablaríamos con toda seguridad de una trascendencia desarticulada, muchas veces parcial y subjetiva, de la experiencia internacional de buena parte de América Latina y de México al principio de uno de los siglos más convulsos y determinantes de la historia humana y sus pueblos. Este centenario bien podría motivar estudios a profundidad de nuestra trayectoria y evolución social en ese pasado reciente que tanto nos explica aún.

\section{Archivos}

AHGE-SRE - Archivo Histórico “Genaro Estrada” de la Secretaría de Relaciones Exteriores, Ciudad de México. AOIT - Archivos de la Oficina Internacional del Trabajo, Ginebra.

\section{Referencias}

BOHÓRQUEZ-MONTOYA, Juan Pablo. Transnacionalismo e historia transnacional del trabajo: hacia una síntesis teórica. Papel Político, v. 14, n. 1, p. 273-301, 2019.

CARUSO, Laura; STAGNARO, Andrés. Una historia regional de la OIT: aportes sobre regulación y legislación del trabajo latinoamericano. La Plata: Universidad Nacional de La Plata, 2017.

CROUCHER, Richard; MCILROY, John. Introduction: beyond national history. Labor History. v. 54, n. 5, p. 485490, 2013.

DION, Michelle. The Political Origins of Social Security in Mexico during the Cárdenas and Ávila Camacho Administrations. Mexican Studies: Estudios Mexicanos, v. 21, n. 1, p. 59-95, 2005.

EDMOND, Martin. The Expatriates. Wellington: Bridget Williams Books, 2017.

FERRERAS, Norberto Osvaldo. La construcción de una Communitas del Trabajo: las relaciones de la Organización Internacional del Trabajo (OIT) y América del Sur durante la década de 1930. Dimensões, v. 29, 2012.

FERRERAS, Norberto Osvaldo. La OIT y los países del Cono Sur en el periodo de entreguerras. Montevideo: Fundación Electra: Fundación de Cultura Universitaria, 2019.

FERRERAS, Norberto Osvaldo. Entre a expansão e a sobrevivência: a viagem de Albert Thomas ao Cone Sul da América. Antíteses, v. 4, n. 7, p. 127-150, 2011.

FERRERAS, Norberto Osvaldo; STAGNARO, Andrés; CARUSO, Laura Gabriela. A Conexão OIT. América Latina: Problemas regionais do trabalho em perspectiva transnacional. Niteroi: Mauad, 2018. 
FRENCH, John D. The Latin American Labor Studies Boom. International Review of Social History, n. 45, p. 279-308, 2000.

GONZÁLEZ MARTíNEZ, Aída. México y la Organización Internacional del Trabajo. Instituto Matías Romero de Estudios Diplomáticos. México y la paz. México: Secretaría de Relaciones Exteriores, p. 86-93, 1986.

HARDY, Henry. Isaiah Berlin. Letters, 1928-1946. Cambridge: Cambridge University Press, 2004.

HERREN, Madeleine. Networking the International System. Basel: Institute for European Global Studies, 2014.

HERRERA GONZÁLEZ, Patricio. En favor de una patria de los trabajadores: la Confederación de Trabajadores de América Latina y su lucha por la emancipación del continente, 1938-1953. Tesis (Doctorado en historia). Zamora: El Colegio de Michoacán, 2013.

HERRERA LEÓN, Fabián; WEHRLI, Yannick. América Latina y el internacionalismo ginebrino de entreguerras: implicaciones y resonancias. México: Dirección General del Acervo Histórico Diplomático de la Secretaría de Relaciones Exteriores, 2019.

HERRERA LEÓN, Fabián. Federico Bach, correspondiente en México de la Oficina Internacional del Trabajo, 1934-1940. In: HERRERA LEÓN, Fabián; HERRERA GONZÁLEZ, Patricio. América Latina y la Organización Internacional del Trabajo: redes, cooperación técnica e institucionalidad social (1919-1950). Morelia: Instituto de Investigaciones Históricas de la Universidad Michoacana de San Nicolás de Hidalgo-Centro de Estudios Históricos de la Universidad de Monterrey - Programa de Pós-Graduação em História da Universidade Federal Fluminense, p. 99-124, 2013.

HERRERA LEÓN, Fabián. Le BIT et l'Amérique latine durant l'entre-deux-guerres: problèmes et enjeux. In: LESPINET MORET, Isabelle; VIET, Vincent. L'Organisation Internationale du Travail en devenir: origine, développement et avenir. Rennes: Presses Universitaires de Rennes, p. 157-166, 2011.

HERRERA LEÓN, Fabián. México y España: mediadores interamericanos de la Sociedad de Naciones (19321935). In: LOPES, Maria-Aparecida; ZULETA, María Cecilia. Mercados en común. Estudios sobre conexiones transnacionales, negocios y diplomacia en las Américas (siglos XIX y XX). México: El Colegio de México, p. 303-342, 2016.

HERRERA LEÓN, Fabián. México y la Organización Internacional del Trabajo: los orígenes de una relación, 1919-1931. Foro Internacional. n. 204, p. 336-355, 2011.

HERRERA LEÓN, Fabián. México y la Sociedad de Naciones: sobre su exclusión e ingreso (1919-1931). Historia Mexicana. v. 69, n. 276, p. 1647-1680, 2020.

HERRERA LEÓN, Fabián. México y la Sociedad de Naciones. Una antología documental. Morelia: Archivo General de la Nación/Secretaría de Relaciones Exteriores-Dirección General del Acervo Histórico Diplomático/Universidad Michoacana de San Nicolás de Hidalgo-Coordinación de la Investigación Científica, 2018.

HERRERA LEÓN, Fabián. Sombras del internacionalismo ginebrino: los correspondientes en México de la Sociedad de Naciones y de la Organización Internacional del Trabajo. In: SUÁREZ ARGÜELLO, Ana Rosa; SÁNCHEZ ANDRÉS, Agustín. A la sombra de la diplomacia. Actores informales en las relaciones internacionales de México, siglos XIX y XX. Morelia: Instituto de Investigaciones Históricas de la Universidad Michoacana de San Nicolás de Hidalgo-Instituto de Investigaciones Dr. José María Luis Mora, p. 239-267, 2017.

HERRERA LEÓN, Fabián; HERRERA GONZÁLEZ, Patricio. América Latina y la Organización Internacional del Trabajo: redes, cooperación técnica e institucionalidad social (1919-1950). Morelia, Instituto de Investigaciones Históricas de la Universidad Michoacana de San Nicolás de Hidalgo: Centro de Estudios Históricos de la Universidad de Monterrey - Programa de Pós-Graduação em História da Universidade Federal Fluminense, 2013.

JENSEN, Jill. From Geneva to the Americas: The International Labor Organization and Inter-American Social Security Standards, 1936-1948. International Labor and Working-Class History, n. 80, p. 215-240, 2011.

KOTT, Sandrine; DROUX, Joëlle. Globalizing Social Rights. The International Labour Organization and Beyond. Hampshire: Palgrave Macmillan, p. 249-261, 2013.

LINDEN, Marcel van der. Globalizing Labour Historiography: the IISH Approach. Ámsterdam: International Institute of Social History, 2002.

LEITÃO, Augusto Rogério. La Organización Internacional del Trabajo (OIT): casi un siglo de acción en diferentes contextos históricos. Laboreal, v. XII, n. 1, p. 103-111, 2016.

LÓPEZ VILLAFAÑE, Víctor. La formación del sistema político mexicano. México: Siglo XXI, 2005. 
MAUL, Daniel. La Organización Internacional del Trabajo. 100 años de políticas sociales a escala mundial. Ginebra: Organización Internacional del Trabajo, 2019.

PLATA-STENGER, Véronique. L'OIT et l'assurance sociale en Amérique latine dans les années 30 et 40 : enjeux et limites de l'expertise internationale. Revue d'histoire de la protection sociale. n. 10, p. 42-61, 2017.

QUIROZ LIZARAN, Eder Said. Los refugiados rusos de la Organización Internacional del Trabajo (1919-1931). Tesis de licenciatura inédita. Morelia: Facultad de Historia de la Universidad Michoacana de San Nicolás de Hidalgo, 2015.

RODGERS, Gerry; LEE, Eddy; SWEPSTON, Lee; VAN DAELE, Jasmien. La Organización Internacional del Trabajo y la lucha por la justicia social, 1919-2009. Ginebra: Oficina Internacional del Trabajo, 2009.

SÁNCHEZ ANDRÉS, Agustín. El espejo invertido: las relaciones hispano-mexicanas durante la segunda República Española (1931-1936). In: SERRA PUCHE, Mari Carmen; MEJÍA FLORES, José Francisco; SOLA AYAPE, Carlos. De la posrevolución mexicana al exilio republicano español. México: Fondo de Cultura Económica, p. 35-52, 2011.

SPENSER, Daniela. En combate: la vida de Lombardo Toledano. México: Debate: Penguin Random House, 2018.

TOLEDO GARCÍA, Itzel. El dilema de la política exterior mexicana: entre la revolución y la estabilización. México y los poderes europeos en la era Obregón-Calles, 1920-28. Tesis (Doctorado en historia). Colchester: University of Essex, 2017.

VAN DAELE, Jasmien; RODRÍGUEZ GARCÍA, Magaly; VAN GOETHEM, Geert; VAN DER LINDEN, Marcel. Essays on the International Labour Organization and Its Impact on the World During the Twentieth Century. Berna: Peter Lang, 2010.

VILLASMIL PRIETO, Humberto. La incidencia de la Organización Internacional del Trabajo en el momento fundacional del derecho del trabajo latinoamericano: unas notas introductorias. Ginebra: Departamento de Relaciones Laborales y de Empleo de la Organización Internacional del Trabajo, 2011

WEHRLI, Yannick. Etats latino-américains, organismes multilatéraux et défense de la souveraineté. Entre Société des Nations et espace continental panaméricain (1919-1939). Tesis (Doctorado en historia). Ginebra: Université de Genève, 2016.

WEINBERG, Pedro Daniel. La OIT en América Latina. Los orígenes de una relación. Montevideo: Fundación Electra: Fundación de Cultura Universitaria, 2019.

YÁÑEZ ANDRADE, Juan Carlos. La OIT en América del Sur. El comunismo y los trabajadores chilenos (19221932). Santiago: Ediciones Universidad Alberto Hurtado, s.a.

ZAPATA, Francisco. Movimientos sociales y conflicto laboral en el siglo XX., In. BIZBERG, Ilán; ZAPATA, Francisco. Los grandes problemas de México: movimientos sociales. México: El Colegio de México, p. 61-99, 2010.

ZAPATA, Francisco. Reseña a Ruth Berins Collier y David Collier. Shaping the Political Arena. Critical Junctures, the Labor Movement, and Regime Dynamics in Latin America. Princeton: Princeton University Press, 1991. Foro Internacional, v. XXXII, n. 4, p. 777-788, 1992.

\section{Notas}

${ }^{1}$ La Conferencia de París admitió prudentemente la creación de una organización permanente de corte reformista y social que velara por las condiciones del trabajo en el mundo y normara al respecto. La Comisión de Legislación Internacional del Trabajo, con la presencia de representantes obreros y destacados líderes sindicales de su tiempo, como Samuel Gompers, su presidente, y George Barnes, representó una corriente dinámica y revolucionaria interna en esta importante ocasión de modelación transnacional, y, a diferencia de la Sociedad de Naciones, no marcó inviables diferencias ni prescindiría del apoyo de las potencias derrotadas en la guerra y des de el momento de su fundación admitió a Alemania y Austria. Su Constitución fue concebida sin contratiempos entre enero y abril de 1919 con base en importantes antecedentes de la llamada “cuestión social”, unionismo y derecho comparado en las últimas décadas, aunque con mayor proximidad a la experiencia de la Asociación Internacional para la Protección Legal de los Trabajadores de Basilea (1901) surgida del Congreso para la protección legal de los trabajadores que tuvo lugar un año antes en París en paralelo con la Exposición Universal. Este documento constitucional fue colocado en la parte XIII del Tratado de Paz (artículos 387-427), y puede consultarse en su versión original en el sitio web de la OIT, disponible en: https://www.ilo.org/public/libdoc/ilo/1920/20B09_18_engl.pdf. Data de acceso en: 5 abr. 2020. Un texto breve, básico y accesible sobre la OIT es (LEITÃO, 2002, p. 103-111). Dos importantes 
estudios especializados a varias manos con excelentes introducciones históricas son (Rodgers; Lee; Swepston; Van Daele, 2009; Van Daele; Rodríguez García; Van Goethem; van der Linden, 2010).

${ }^{2}$ Por sus siglas en francés (Bureau International du Travail) y para distinguirla de la OIT, cuyos acrónimos son homónimos en español e inglés.

${ }^{3}$ Apenas pueden mencionarse las siguientes iniciativas de investigación (González Martínez, 1986, p. 86-93; Herrera León, 2011, p. 336-355; Spenser, 2018; Herrera González, 2013; Herrera León, 2013, p. 99-124).

${ }^{4}$ La Ginebra internacional y sus principales organizaciones han sido estudiadas abundantemente, aunque con un especial ánimo de revisión y replanteamiento metodológico e historiográfico en años recientes. Entre las obras destacadas referidas por completo o parcialmente a América Latina se encuentran las siguientes: (Van Daele; Rodríguez García; Van Goethem; van der Linden, 2010; Herrera León; Wehrli, 2011, p. 157-166; Ferreras, 2011, p. 127-150; Jensen, 2011, p. 215 240; Villasmil Prieto, 2011; Ferreras, 2012, p. 3-21; Herrera León; Herrera González, 2013; Kott; Droux, 2013; Wehrli, 2016 ; Caruso; Stagnaro, 2017; Plata-Stenger, 2017, p. 42-61; Ferreras; Stagnaro; Caruso, 2018; Fink; Palacio, 2018; Herrera León; Wehrli, 2019; Weinberg, 2019; Maul, 2019; Yáñez Andrade, s.a).

${ }_{5}^{5}$ Para especialistas del trabajo como Alberto Trueba es evidente la influencia de los derechos sociales contenidos en el artículo 123 de la Constitución mexicana en los propósitos y principios contenidos en el articulado constitutivo de la OIT en el Tratado de Versalles; una cuestión ciertamente relevante bajo una óptica nacionalista, pero que pierde parte importante de su peso cuando reflexionamos en las ideas occidentales ya circulantes que a su vez influyeron en el célebre artículo laboral mexicano (Trueba Urbina, 1987, p. 933-947).

${ }^{6}$ Un excelente trabajo de investigación sobre este complicado proceso reformista es (Dion, 2005, p. 59-95).

${ }^{7}$ Pongo por ejemplo la lectura de uno de los textos más notables de los 1990 y los cuestionamientos a su demostración de la tesis de la incorporación regional del movimiento obrero latinoamericano (Zapata, 1992, p. 777-788).

${ }^{8}$ Cecilia Montero Casassus permite hacerse una idea de ello en vista de la atención académica en problemas complejos relacionados con el trabajo y las sociedades latinoamericanas, así como la coexistencia de diversos paradigmas, escuelas interpretativas y fenómenos de atención en (Montero Casassus, 1994, p. 71-89).

${ }^{9}$ Entiéndase la Sociedad de Naciones y toda suerte de organizaciones con diversos propósitos, técnicos, sociales y humanitarios que al menos gozaron de una distinción semi oficial y conformaron la "familia de la Sociedad de Naciones" (Herren, 2014, p. 5).

${ }^{10}$ La dimensión más amplia de los programas de seguridad social entre las naciones industrializadas más avanzadas comprendería igualmente el seguro por desempleo y apoyos familiares (Dion, 2005, p. 61).

${ }^{11}$ El atractivo de Europa para la etapa de la revolución bajo influencia de los presidentes sonorenses Álvaro Obregón y Plutarco E. Calles ha sido replanteada recientemente en un estudio que aparecerá próximamente publicado bajo el sello del Acervo de la Secretaría de Relaciones Exteriores de México (Toledo García, 2017).

${ }^{12}$ Sucesor de Antonio Castro Leal en este puesto, quien construyó una relación armoniosa con la OIT y asistió oficialmente como observador a la Conferencia Internacional del Trabajo de junio de 1930. Genaro Estrada, secretario de Relaciones Exteriores, a Luis L. León, secretario de Industria, Comercio y Trabajo, México D. F., 9 de junio de 1930, Archivo Histórico Genaro Estrada, de la Secretaría de Relaciones Exteriores (en adelante AHGE-SRE), exp. III-1854-3.

${ }^{13} \mathrm{Y}$ como muestra de estos impertinentes juicios e impresiones personales, que, pese a su deseo de ser nombrado ministro en Ginebra, solo desaparecerían con su traslado inesperado a Centroamérica, Martínez de Alba se permitía este tipo de formulaciones: “Privadamente, y de una manera enteramente confidencial he sabido que la Oficina Internacional del Trabajo, que en tiempos del Sr. Thomas descuidó mucho a la América Latina y, en general a todos los países de ultramar, se ocupa en estos momentos de estudiar la conveniencia de organizar una Conferencia [...]". Martínez de Alba al secretario de Relaciones Exteriores, Ginebra, 12 de julio de 1932, AHGE-SRE, exp. III-471-9. Y al informar de su asistencia al propio funeral de Thomas el 9 de abril en Champigny no tendría el menor bochorno en elevar a un plano oficial sus conflictos personales: "Las personas que conocen las relaciones que existen entre México y el Sr. Thomas [...] encontraron sumamente digno y encomiable el gesto de México". Salvador Martínez de Alva al secretario de Relaciones Exteriores de México, Ginebra, 17 de mayo de 1932, AHGE-SRE, exp. III-1854-3. Algunos informes relevantes de Martínez de Alba con esta "marca personal" forman parte del compendio (HERRERA LEÓN, 2018).

${ }^{14}$ Emilio Portes Gil al secretario de Relaciones Exteriores, París, 18 de diciembre de 1931, AHGE-SRE, exp. III-471-9.

${ }^{15}$ Manuel C. Téllez, secretario de Relaciones Exteriores al secretario de Industria, Comercio y Trabajo, "Sobre ratificación de Convenciones del trabajo", México, D. F., 4 de febrero de 1932, AHGE-SRE, exp. III-1854-3.

${ }^{16}$ Albert Thomas a Emilio Portes Gil, Ginebra, 26 de noviembre de 1931, AHGE-SRE, exp. III-1854-3; Telegrama de Emilio Portes Gil a la Secretaría de Relaciones Exteriores, París, 27 de noviembre de 1931, AHGE-SRE, exp. III-1854-3; Emilio Portes Gil al secretario de Relaciones Exteriores, París, 18 de diciembre de 1931, AHGE-SRE, exp. III-471-9. Se trataba 
de diversas convenciones y recomendaciones emanadas de las primeras quince reuniones de la Conferencia Internacional del Trabajo (1919-1931), principalmente, de las siguientes: Sobre el trabajo nocturno de las mujeres, 1919; Sobre las indemnizaciones de desempleo (naufragio), 1920; Sobre la colocación de la gente de mar, 1920; Sobre el derecho de asociación (agricultura), 1921; Sobre la indemnización por accidentes del trabajo (agricultura), 1921; Sobre la cerusa (pintura), 1921; Sobre el descanso semanal (industria), 1921; Sobre el examen médico de los menores (trabajo marítimo), 1921; Sobre la indemnización por accidentes de trabajo, 1925; Sobre la igualdad de trato (accidentes de trabajo), 1925; Sobre la inspección de los emigrantes, 1926; Sobre el contrato de enrolamiento de la gente de mar, 1926; Sobre la repatriación de la gente de mar, 1926; Sobre los métodos para la fijación de salarios mínimos, 1928; Sobre la indicación del peso en los fardos transportados por barco, 1929; Sobre trabajos forzados y obligatorios, 1930 y Sobre las horas de trabajo en el comercio y oficinas, 1930.

${ }_{17}^{17}$ Secretario de Relaciones Exteriores a secretario de Industria, Comercio y Trabajo, México, D. F., 9 de noviembre de 1931, AHGE-SRE, exp. III-1854-3.

${ }^{18}$ Primo Villa Michel, subsecretario de la Secretaría de Industria, Comercio y Trabajo, al secretario de Relaciones Exteriores, México, D. F., 10 de febrero de 1932, AHGE-SRE, exp. III-1854-3.

19 Telegrama de Albert Thomas al secretario de Relaciones Exteriores de México, Ginebra, 22 de marzo de 1932, AHGE-SRE, exp. III-1854-3.

${ }^{20}$ Estos fueron Romeo Ortega y Leopoldo Blasquez, designados por la Secretaría de Industria, Comercio y Trabajo tras la consulta particular de la cancillería en respuesta a la petición de Thomas. Ortega y Blasquez se encontraban ya en Europa en calidad de ministro en Suecia y de encargado de negocios en Checoslovaquia, respectivamente. Ortega no podría asistir finalmente a la Conferencia y en su lugar fue nombrado Francisco Castillo Nájera, ministro en Holanda. Albert Thomas al secretario de Relaciones Exteriores de México, Ginebra, 24 de noviembre de1931, AHGE-SRE, exp. III-1854-3; Primo Villa Michel, subsecretario de la Secretaría de Industria, Comercio y Trabajo, al secretario de Relaciones Exteriores, México, D. F., 3 de marzo de 1932, AHGE-SRE, exp. III-1854-3; secretario de Relaciones Exteriores al secretario de Industria, Comercio y Trabajo, México, D. F., 5 de marzo de 1932, AHGE-SRE, exp. III-1854-3; Telegrama del secretario de Relaciones Exteriores al secretario de Industria, Comercio y Trabajo, México, D. F., 28 de marzo de 1932, AHGE-SRE, exp. III-1854-3; Primo Villa Michel, subsecretario de la Secretaría de Industria, Comercio y Trabajo, al secretario de Relaciones Exteriores, México, D. F., 29 de marzo de 1932, AHGE-SRE, exp. III-1854-3; telegrama de Relaciones a Observamex, México, D. F., 30 de marzo de 1932, AHGE-SRE, exp. III-1854-3.

${ }^{21}$ Martínez de Alva a la Secretaría de Relaciones Exteriores, Ginebra, 6 de febrero de 1932, AHGE-SRE, exp. III-1854-3.

22 Plutarco E. Calles al secretario de Relaciones Exteriores, Cuyutlán, 30 de marzo de 1932, AHGE-SRE, exp. III-1854-3. Manuel C. Téllez le daría la siguiente explicación al tutor protagonista del Maximato: "Sobre materia tengo que informar a usted que Secretaría Industria Comercio y Trabajo fue quien designó Comisión próxima reunión Trabajo Ginebra, habiendo esta Secretaría por su parte presentado iniciativas y hecho todo esfuerzo para que Delegación enviárase completa. Ya transcribo Industria su telegrama". Manuel C. Téllez a Plutarco E. Calles, México, D. F., 30 de marzo de 1932, AHGE-SRE, exp. III-1854-3. El canciller agregaría después problemas de presupuesto tras una consulta puntual a la Secretaría de Comercio, Industria y Trabajo. Abelardo L. Rodríguez, secretario de Comercio, Industria y Trabajo al secretario de Relaciones Exteriores, México, D. F., 1 de abril de 1932, AHGE-SRE, exp. III-1854-3 y telegrama de Manuel C. Téllez a Plutarco E. Calles, México, D. F., 5 de abril de 1932, AHGE-SRE, exp. III-1854-3.

${ }^{23}$ Los delegados obreros cubano, Arévalo, y belga, Martens, sí hicieron esta crítica pública en distintas exposiciones tras la apertura de Conferencia. Francisco Castillo Nájera al secretario de Relaciones Exteriores, "Informa sobre la XVIa Conferencia Internacional del Trabajo", Ginebra, 3 de mayo de 1932, AHGE-SRE, exp. III-1854-3. Leopoldo Blasquez pudo realizar una aclaración puntual en la sesión plenaria de la Conferencia en respuesta al señalamiento del representante obrero belga, enfatizando: “[...] mi gobierno no supo sino hasta el mes de enero último la fecha de la presente reunión, fecha que se ha adelantado más de dos meses, y que, por este motivo, y a causa, además, de la extensión del territorio mexicano y del gran número de organizaciones obreras importantes que en él existen, le ha sido materialmente imposible determinar con estas organizaciones, en un plazo de solo unas semanas, la designación del delegado obrero. [...] Por otra parte, no es posible acusar a mi gobierno de ejercer presión de ningún género sobre la clase obrera - lo que ella no permitiría -; nuestra legislación protege, respeta y hace respetar todos los derechos de los obreros, y dicha legislación es una de las más liberales y de las más favorables para las clases trabajadoras. En lo futuro, el gobierno mexicano, cumpliendo con su deber, hará todo lo posible para enviar una delegación completa a la Conferencia Internacional del Trabajo. Leopoldo Blasquez, encargado de negocios ad-hoc en Checoslovaquia, a la Secretaría de Relaciones Exteriores, "Informe sobre la décima sexta Conferencia Internacional del Trabajo, reunida en Ginebra del 12 al 30 de abril de 1932", Praga, 27 de mayo de 1932, AHGE-SRE, exp. III-1854-3.

${ }^{24}$ Francisco Castillo Nájera al secretario de Relaciones Exteriores, “Informa sobre la XVIa Conferencia Internacional del Trabajo", Ginebra, 3 de mayo de 1932, AHGE-SRE, exp. III-1854-3. 
${ }^{25}$ Francisco Castillo Nájera al secretario de Relaciones Exteriores, "Informa sobre la XVla Conferencia Internacional del Trabajo", Ginebra, 3 de mayo de 1932, AHGE-SRE, exp. III-1854-3, anexo 6.

26 “Tienen la obligación terminante todos los Estados miembros de enviar a la Conferencia sus delegaciones completas, pues de lo contrario puede verse comprometido el equilibrio previsto por el Tratado de Paz". Oficial mayor de la Secretaría de Relaciones Exteriores al secretario de Industria, Comercio y Trabajo, México, D. F., 28 de junio de 1932, AHGE-SRE, exp. III-1854-3.

${ }^{27}$ Idem.

${ }^{28}$ Primo Villa Michel a secretario de Relaciones Exteriores, México, D. F., 6 de julio de 1932, AHGE-SRE, exp. III-1854-3.

${ }^{29}$ Antonio Hidalgo B., oficial mayor del Departamento del Trabajo, al secretario de Relaciones Exteriores, "Comunicando la integración de la delegación mexicana que asistirá a la Conferencia Internacional del Trabajo”, México, D. F., 28 de marzo de 1933, AHGE-SRE, exp. III-1854-4 (I).

${ }^{30}$ Acuerdo del presidente de México, Abelardo L. Rodríguez, destinado al jefe del Departamento del Trabajo, con copia para el secretario de Relaciones Exteriores, Palacio Nacional, 7 de marzo de 1933, AHGE-SRE, exp. III-1854-4 (I).

${ }^{31}$ Paul Devinat a Albert Thomas, "Voyage Devinat au Mexique: Établissement d'Emigrés”, Ginebra, 24 de mayo de 1925, Archivos de la Oficina Internacional del Trabajo (en adelante AOIT), Cabinet Albert Thomas (en adelante CAT) 5-52-2, dossier: Mexique: Informations diverses, établissement de réfugiés/Mexique. (Quiroz Lizaran, 2015).

${ }^{32}$ Francisco Castillo Nájera al secretario de Relaciones Exteriores, París, 7 de abril de 1933, AHGE-SRE, exp. III-499-6.

${ }^{33}$ Harold Butler al secretario de Relaciones Exteriores, Ginebra, 28 de abril de 1933, AHGE-SRE, exp. III-499-6.

${ }^{34}$ Edward J. Phelan, Confidential: Note on Trade Union Organisation in Mexico, AOIT/Archivos de Edward J. Phelan (en adelante AEJP), dossier: Reports on Missions to Canada, U.S., México.

${ }^{35} \mathrm{Idem}$

${ }^{36}$ Edward J. Phelan. Confidential: Note on Trade Union Organisation in Mexico. AOIT/AEJP, dossier: Reports on Missions to Canada, U.S., México.

${ }^{37}$ Edward J. Phelan. Confidential: Note on Trade Union Organisation in Mexico. AOIT/AEJP, dossier: Reports on Missions to Canada, U.S., México.

${ }^{38}$ Tal fue el caso de la Federación de Uniones Comeciales del Distrito Federal, filial de la Cámara Nacional del Trabajo, que reunió 300 funcionarios y trabajadores y una demostración pública con airados discursos contra la CROM. También se hizo una visita a la Confederación de Cámaras Industriales (CONCAMIN), bien familiarizada con la OIT y sin expectativas respecto del régimen posrevolucionario existente.

${ }^{39}$ Edward J. Phelan. Confidential: Note on Trade Union Organisation in Mexico. AOIT/AEJP, dossier: Reports on Missions to Canada, U.S., México. Se hace referencia a un acuerdo de reforma de octubre de 1922 al artículo 393 del Tratado de Versalles, concerniente a la integración del Consejo de Administración de la organización y la resolución de disputas relacionadas con las disputas de representatividad en los ámbitos patronal y obrero.

${ }^{40}$ Edward J. Phelan. Confidential: Note on Trade Union Organisation in Mexico. AOIT/AEJP, dossier: Reports on Missions to Canada, U.S., México.

${ }^{41}$ Las relaciones hispano-mexicanas en esta etapa son estudiadas en (Sánchez Andrés, 2011, p. 35-52); mientras que la colaboración de ambos regímenes llevada a Ginebra es estudiada en (Herrera León, 2016, p. 303-342).

${ }^{42}$ Edward J. Phelan. Confidential: Note on Trade Union Organisation in Mexico. AOIT/AEJP, dossier: Reports on Missions to Canada, U.S., México.

${ }^{43}$ Idem.

${ }^{44}$ (PLATA-STENGER, 2017, p. 48).

${ }^{45}$ Además de ofrecer un minucioso y bien logrado estudio sobre la cuestión, Michelle Dion rescata lo expresado coloquialmente por el presidente Cárdenas a su insistente ministro de Gobernación, Ignacio García Téllez, futuro secretario del Trabajo en el gobierno posterior de Manuel Ávila Camacho y segundo director del Instituto Mexicano del Seguro Social: "No Licenciado, serían dos toros puntales que tendríamos que lidiar al mismo tiempo... Vamos sacando primero el petróleo en bien de la nación y a su tiempo será el Seguro". (Dion, 2005, p. 67).

${ }^{46}$ Convenio relativo a la reparación de los accidentes del trabajo (séptima reunión, Ginebra, 19 de mayo al 10 de junio de 1925); Convenio relativo a la igualdad de trato a los trabajadores extranjeros y nacionales (séptima reunión, Ginebra, 19 de mayo al 10 de junio de 1925); Convenio relativo al contrato de alistamiento de los marinos (novena reunión, Ginebra, 7 al 24 de junio de 1926); Convenio relativo a la repatriación de los marinos (novena reunión, Ginebra, 7 al 24 de junio de 1926); 
Convenio relativo a la institución de métodos para la fijación de salarios mínimos (décima primera reunión, Ginebra, 30 de mayo al 16 de junio de 1928); Convenio relativo a la institución de métodos para la fijación de salarios mínimos (décima primera reunión, Ginebra, 30 de mayo al 16 de junio de 1928); Convenio relativo a la indicación del peso de los grandes bultos transportados por barcos (décima segunda reunión, Ginebra, 30 de mayo al 21 de junio de 1929); Convenio relativo a la protección de trabajadores ocupados en la carga y descarga de los buques, contra los accidentes (décima segunda reunión, Ginebra, 30 de mayo al 21 de junio de 1929. Revisado en 1932); Convenio relativo al trabajo forzoso u obligatorio (décima cuarta reunión, Ginebra, 18 al 28 de junio de 1930); Convenio relativo a la reglamentación de la duración del trabajo en el comercio y en las oficinas (décima cuarta reunión, Ginebra, 18 al 28 de junio de 1930); Reforma al artículo 393 del Tratado de Versalles y a los artículos correspondientes de otros Tratados de Paz (cuarta reunión, Ginebra, 2 de noviembre de 1922). Manuel C. Téllez a subsecretario Encargado del Despacho de Gobernación, "Se envían convenios de la Conferencia General del Trabajo para su aprobación por el Senado", México, D. F., 8 de diciembre de 1932, en AHGE-SRE, exp. III-1853-1. También en III-1854-1.

${ }^{47}$ Sociedad de Naciones, Ginebra, 7 de junio de 1934, comunicado informativo del secretariado C.L84.1934. V y Manuel J. Sierra, jefe del Departamento de Asuntos Políticos, Sección de Tratados al jefe del Departamento Jurídico, memorándum, México, D. F., 11 de junio de 1934, AHGE-SRE, exp. III-1853-1.

Recebido em: 25/04/2020

Aprovado em: 02/06/2020 